\title{
Linking transcriptomics and proteomics in spermatogenesis
}

\author{
Frédéric Chalmel and Antoine D Rolland \\ Inserm U1085-Irset, Université de Rennes 1, F-35042 Rennes, France \\ Correspondence should be addressed to F Chalmel; Email: frederic.chalmel@inserm.fr or to \\ A D Rolland; Email: antoine.rolland@univ-rennes1.fr
}

\begin{abstract}
Spermatogenesis is a complex and tightly regulated process leading to the continuous production of male gametes, the spermatozoa. This developmental process requires the sequential and coordinated expression of thousands of genes, including many that are testisspecific. The molecular networks underlying normal and pathological spermatogenesis have been widely investigated in recent decades, and many high-throughput expression studies have studied genes and proteins involved in male fertility. In this review, we focus on studies that have attempted to correlate transcription and translation during spermatogenesis by comparing the testicular transcriptome and proteome. We also discuss the recent development and use of new transcriptomic approaches that provide a better proxy for the proteome, from both qualitative and quantitative perspectives. Finally, we provide illustrations of how testis-derived transcriptomic and proteomic data can be integrated to address new questions and how the 'proteomics informed by transcriptomics' technique, by combining RNA-seq and MS-based proteomics, can contribute significantly to the discovery of new protein-coding genes or new protein isoforms expressed during spermatogenesis.

Reproduction (2015) 150 R149-R157
\end{abstract}

\section{Introduction: unraveling testis specificities with omics technologies}

From a genomist's point of view, spermatogenesis, especially in mammals, is arguably one of the most exciting objects of study available. Not only does this developmental process offer incredible molecular dynamics, but it also embodies several expression specificities and striking genomic features.

To make motile sperm capable of fertilization, germ cells must undergo unique processes, such as meiosis, and develop specific organelles and cell structures, including the acrosome, flagellum, and a highly condensed nucleus. This extreme differentiation process involves the functions of specific molecular factors, many of them expressed only during spermatogenesis. High-throughput tissue-profiling experiments thus regularly identify the testis as the organ that expresses the greatest number of tissue-specific genes and proteins (Chalmel et al. 2007, 2012, Kouadjo et al. 2007, Fagerberg et al. 2014, Uhlen et al. 2015). Similarly, the finding that the testis contains the highest number of alternative splicings (Xu et al. 2002, Yeo et al. 2004, Kan et al. 2005, De la Grange et al. 2010) indicates that what is true for genes and proteins also applies to isoforms.

Evolutionarily speaking, genes involved in male germ cell development are also quite remarkable. For instance, testis-expressed genes show the highest divergence rate between species for both sequence and expression (Khaitovich et al. 2005, Voolstra et al. 2007). Additionally, testicular transcripts have, yet again, the highest number of diverged alternative splicings (Kan et al. 2005). This fast evolution of male fertility-related factors is thought to result from sexual selection, a specific pressure selection that enables mutations providing a reproductive advantage to be transmitted more easily to progeny and thus fixed within a species relatively quickly.

Another striking genomic feature observed during germ cell development concerns sexual chromosomes and especially X-linked genes (for review, see $\mathrm{Hu}$ \& Namekawa (2015)). Throughout the evolution of eutherian species, the $\mathrm{Y}$ chromosome has become progressively shorter, thus preventing the $X$ and $Y$ chromosomes from aligning/pairing with any precision during meiotic prophase I. Accordingly, to prevent misalignments and recombinations, sexual chromosomes condense into a specific nuclear structure named the sex- or XY-body (Solari 1974, McKee \& Handel 1993). The strong condensation of $X$ and $Y$ chromosomes within this structure leads to their complete transcriptional silencing (Turner 2007). This so-called meiotic sex chromosome inactivation (MSCl) has been demonstrated clearly at the genome-wide 
level: several high-throughput expression studies have failed to find the expression of a single $X$-linked gene during the meiotic phase of spermatogenesis (Namekawa et al. 2006, Chalmel et al. 2007). Additionally, to compensate for the cessation of transcription of crucial genes for any cell, a large number of X-linked genes have, over the course of evolution, been transposed onto autosomes and acquired specific meiotic and post-meiotic expression (Potrzebowski et al. 2008, 2010). Finally, because the heterozygous nature of sexual chromosomes in males allows advantageous reproductive traits to be fixed quickly, X-linked genes are overrepresented among those preferentially expressed in testicular somatic cells, spermatogonia, and post-meiotic spermatids (Khil et al. 2004, Chalmel et al. 2007, Mueller et al. 2008).

Taken together, the specificities of the male germ cell expression program provide a rich environment for studying regulatory mechanisms of gene expression at various levels as well as for the discovery of new genes and protein isoforms. As many past studies investigating spermatogenesis with high-throughput approaches have been reviewed elsewhere (Rolland et al. 2008, Calvel et al. 2010, Chocu et al. 2012), here we focus on studies that have attempted to link the transcriptome and proteome in spermatogenesis or have combined transcriptomic and proteomic data to gain insight into testicular functions and germ cell biology (Table 1).

\section{Integrative omics strategies to study spermatogenesis}

The integration of various types of omics data, e.g. epigenomic, transcripomic, proteomic, interactomic, or regulomic, represents a powerful tool for going far beyond basic descriptive analyses. Combining information from different samples and technologies makes it possible to improve data consistency by refining candidate selection, as well as to address more specific questions and to build new hypotheses (Fig. 1A).

For example, microarray and proteomic data from mouse testes lacking DICER in the Sertoli cells $\left(D C R^{f x / f x} ; M i s C r e\right)$ were compared to investigate the miRNA-mediated post-transcriptional regulation in these cells (Papaioannou et al. 2011). This approach allowed the authors to identify miRNA-targets within Sertoli cells, i.e. proteins whose abundance increases in $\mathrm{KO}$ mice, even

Table 1 Overview of studies linking transcriptomics and proteomics in spermatogenesis.

\begin{tabular}{|c|c|c|c|}
\hline Study & Samples & Technology & Main findings \\
\hline \multicolumn{4}{|l|}{ Integrative omics analyses } \\
\hline $\begin{array}{l}\text { Papaioannou et al. } \\
\text { (2011) }\end{array}$ & Mouse testis & Microarray, ICPL-proteomics & $\begin{array}{l}\text { Identification of miRNA-mediated translationally- } \\
\text { regulated genes in Sertoli cells }\end{array}$ \\
\hline Chalmel et al. (2012) & Human tissues & $\begin{array}{l}\text { Microarray, antibody-based } \\
\text { proteomics }\end{array}$ & $\begin{array}{l}\text { Identification of differentially-expressed testis- } \\
\text { specific proteins during spermatogenesis }\end{array}$ \\
\hline Rolland et al. (2013) & $\begin{array}{l}\text { Human semen } \\
\text { and tissues }\end{array}$ & Microarray, MS/MS-proteomics & $\begin{array}{l}\text { Identification of genital tract protein markers in the } \\
\text { seminal plasma }\end{array}$ \\
\hline Wang et al. (2013) & Human sperm and tissues & Microarray, MS/MS-proteomics & Identification of testis-specific sperm proteins \\
\hline Chalmel et al. (2014) & $\begin{array}{l}\text { Rat/ram testicular cells } \\
\text { and fluid }\end{array}$ & Microarray, MS/MS-proteomics & $\begin{array}{l}\text { Identification of extracellular proteins involved in } \\
\text { the germ cell-Sertoli cell crosstalk }\end{array}$ \\
\hline Djureinovic et al. (2014) & Human tissues & Antibody-based proteomics, RNA-seq & Identification of testis-specific proteins \\
\hline \multicolumn{4}{|c|}{ Transcriptome and proteome correlation analyses } \\
\hline Cagney et al. (2005) & Human tissues & Microarray, MudPIT proteomics & $\begin{array}{l}\text { Identification of the testis as the tissue with the } \\
\text { lowest transcriptome/proteome correlation }\end{array}$ \\
\hline Gan et al. (2013a) & Mouse male germ cells & Microarray, iTRAQ proteomics & $\begin{array}{l}\text { Identification of post-transcriptionally-regulated } \\
\text { genes during germ cell development }\end{array}$ \\
\hline \multicolumn{4}{|c|}{ Post-transcriptional regulation analyses } \\
\hline Reynolds et al. (2005) & Rat testis & CLIP, microarray & Identification of DAZL direct targets \\
\hline Grellscheid et al. (2011) & Mouse testis & CLIP, RNA-seq & Identification of TRA2B direct targets \\
\hline Vourekas et al. (2012) & Mouse testis & CLIP, RNA-seg & Identification of PIWIL1 and PIWIL2 direct targets \\
\hline Zhang et al. (2015) & Mouse spermatids & CLIP, RNA-seq & Identification of PIWIL1 direct targets \\
\hline \multicolumn{4}{|l|}{ Translatome analyses } \\
\hline Iguchi et al. (2006) & Mouse testis & RNPs/polysomes, microarray & $\begin{array}{l}\text { Identification of translationally regulated mRNAs } \\
\text { during meiosis and spermiogenesis }\end{array}$ \\
\hline Sanz et al. (2013) & Mouse testis & RiboTag, microarray & $\begin{array}{l}\text { Identification of } \mathrm{LH}-, \mathrm{FSH} \text { - and testosterone-regu- } \\
\text { lated genes translated in Leydig and Sertoli cells }\end{array}$ \\
\hline De Gendt et al. (2014) & Mouse testis & RiboTag, RNA-seq & $\begin{array}{l}\text { Identification of androgen receptor-regulated genes } \\
\text { translated in Sertoli cells }\end{array}$ \\
\hline Evans et al. (2014) & Mouse testis & RiboTag, microarray & $\begin{array}{l}\text { Identification of retinoic acid-regulated genes } \\
\text { translated in Sertoli cells and germ cells }\end{array}$ \\
\hline \multicolumn{4}{|c|}{ Proteomics informed by transcriptomics analyses } \\
\hline Palmer et al. (2013) & Red abalone testis & RNA-seq, MS/MS proteomics & $\begin{array}{l}\text { Identification of testicular proteins in a non-model } \\
\text { organism (unsequenced genome) }\end{array}$ \\
\hline Chocu et al. (2014) & Rat male germ cells & RNA-seq, MS/MS proteomics & $\begin{array}{l}\text { Identification of novel protein-coding genes in the } \\
\text { rat genome }\end{array}$ \\
\hline
\end{tabular}

CLIP, cross-linking immuno-precipitation; ICPL, isotope-coded protein labeling; iTRAQ, isobaric tags for relative and absolute quantitation; RNPs, ribonucleoprotein particles; MS/MS, tandem mass spectrometry; MudPIT, multidimensional protein identification technology. 
A

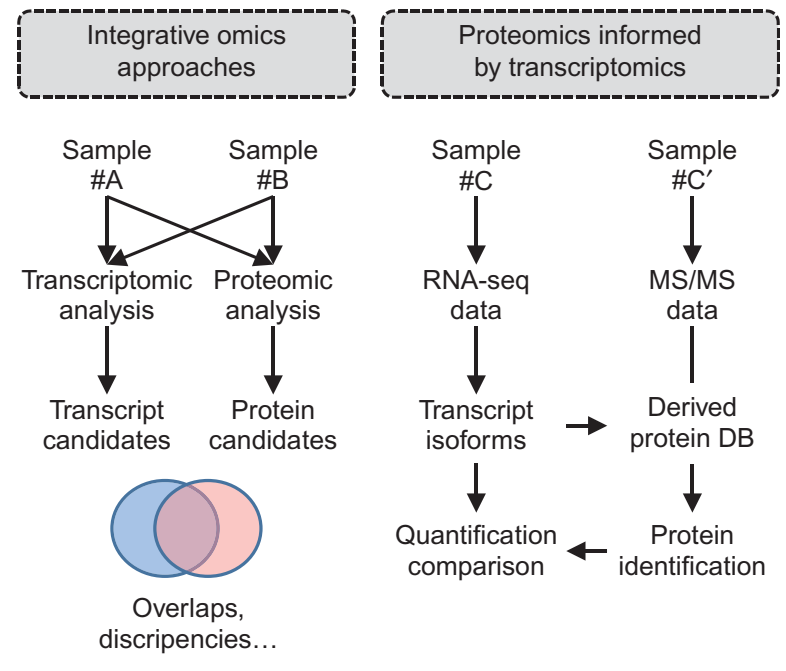

B

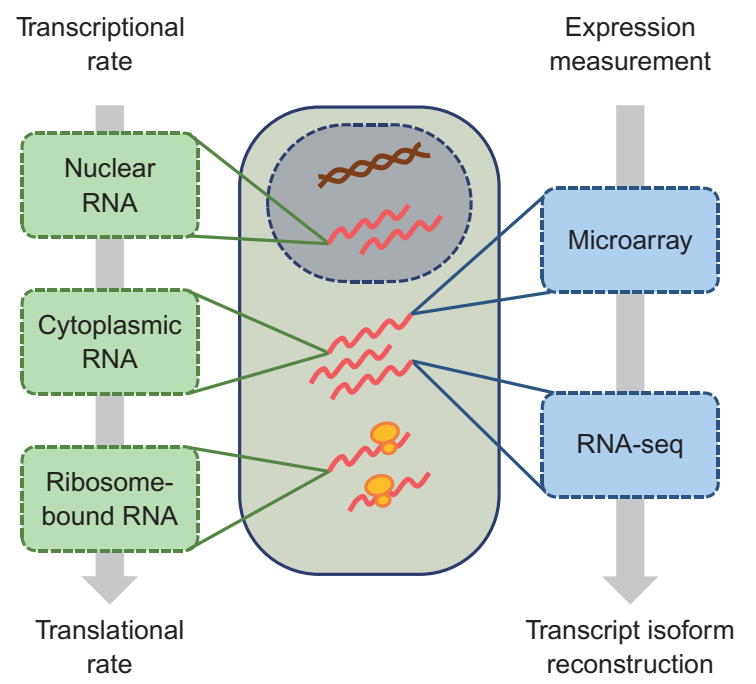

Figure 1 When transcriptomics meets proteomics. (A) Typical integrative omics approaches involve the combination of datasets originating from various technologies, most notably transcriptomics and proteomics. Such strategies are often used to identify more reliable candidates (i.e. factors evidenced at both the RNA and protein levels), but they can also be useful in order to compare and correlate transcription and translation rates. More recently, the combination of RNA-seq and mass spectrometry (MS)-based proteomic has led to the development of the so-called proteomics informed by transcriptomics (PIT) approach. In this approach, the protein sequence database (DB) queried for protein identification purpose is directly derived from transcript sequences obtained following RNA-seq analysis of the same or equivalent sample as that used for MS/MS analysis. (B) The characterization of the transcriptome has long been used as a proxy for the proteome. However, depending on whether nuclear, total cytoplasmic, or ribosome-bound RNAs are analysed, the captured picture will reflect either more the transcriptional rate or the translational rate. Additionally, while both approaches perform equivalently from a quantitative point of view, RNA-seq overcomes microarray technology from a qualitative point of view as it allows full-length transcript reconstruction and can thus discriminate between distinct protein-coding isoforms. though the expression of their corresponding mRNAs does not change. Subsequently, they performed 3'UTR luciferase assays to validate SOD-1 as a likely direct target of miR-125a-3p, miR-872 and miR-24.

Many studies have also combined proteomic and transcriptomic data to improve the characterization of the expression landscape during spermatogenesis. Chalmel et al. (2012) using biopsies from infertile patients with spermatogenesis arrested at various stages of germ cell development, first identified genes preferentially expressed in each type of testicular cell. Gene expression data from various tissues and antibody-based profiling data from the Human Protein Atlas (http://www. proteinatlas.org; Uhlen et al. 2010) were then used to identify, respectively, the genes and gene products showing testis-specific expression; most of them were found to be expressed in meiotic and post-meiotic germ cells. Finally, taking advantage of available information on protein-gene interactions (i.e. regulomic data), these authors filtered for a core network of transcription factors and DNA-binding proteins that are likely to drive the germ cell-specific expression program. Conversely, Djureinovic et al. (2014) sought to determine the human testis-specific proteome, beginning with the RNA-sequencing (RNA-seq) analysis of 27 tissues. They then interrogated the Human Protein Atlas about the testis-enriched transcripts they identified to confirm the testis-specificity of corresponding protein products and to identify the testicular cell type(s) in which they were expressed.

The combination of transcriptomic and proteomic approaches has also been very successful in helping to interpret the content of biological fluids or transcriptionally-inactive cells, such as spermatozoa. For instance, Rolland et al. (2013) compiled several human seminal plasma proteomic studies and compared the resulting proteome to gene expression data for the organs contributing to this biological fluid, i.e. the testis, epididymis, seminal vesicle, and prostate. This allowed the identification of protein biomarkers for each of the male genital tract organs. Importantly, these biomarkers, including germ cell markers, can thus be monitored in semen.

A recent investigation of the intricate question of Sertoli-germ cell communication used another such integrative approach (Chalmel et al. 2014a). It analyzed the testicular fluid proteome of rats and rams and then combined it with transcriptomic data from isolated testicular cells (Chalmel et al. 2007) and with proteinprotein interaction data. The authors were therefore able to identify testicular fluid proteins likely to be secreted by Sertoli cells and to interact with germ cell membrane proteins and, conversely, proteins secreted by germ cells that might interact with Sertoli cell membrane proteins. Among these, the interactions of $\mathrm{APOH}$ and CDC42 as well as APP and NGFR were further investigated and validated in situ. Finally, Wang et al. (2013) compiled 
several proteomic studies to determine the proteome of human spermatozoa and used gene expression tissueprofiling data to identify the sperm proteins specifically expressed in the testis. With this candidate list, they next queried the drug target information available in Drugbank (Wishart et al. 2008) to identify potential male contraceptive molecules. Disulfiram and propofol, two molecules thought to target cilia proteins, were then shown to inhibit sperm motility.

\section{Correlating transcription and translation rates during spermatogenesis}

Transcriptomic studies often assume that the abundance of mRNAs and that of their corresponding proteins are well correlated. This hypothesis is considered to justify extrapolation from changes in gene expression to changes in protein expression and, ultimately, to their potential functional impact. The rationale of this hypothesis may appear quite reasonable: typical microarray or RNA-seq protocols involve an oligo-dT selection of polyadenylated mRNAs, which are thought to be actively translated, unlike those that are not polyadenylated.

The fate of an mRNA, however, is tightly regulated by a complex interplay of modification, processing, storage, decay, and translation, all involving protein-RNA interactions through messenger ribonucleoprotein (mRNP) complexes. Some of these assembled complexes are conducted directly to translation while others are diverted towards storage and translational repression (for review, see Müller-McNicoll \& Neugebauer (2013)).

While post-transcriptional and translational gene regulation is a common mechanism in all cell types, it is especially striking during spermatogenesis. As spermatids start to elongate, nuclear histones are sequentially replaced by transition proteins and protamines (for review, see Rathke et al. (2014)). This substitution allows the progressive condensation of chromatin and thus leads to the complete cessation of transcription from mid-spermiogenesis onwards (Kierszenbaum \& Tres 1975). As a consequence, many genes that are required for the development and/or functioning of spermatozoa are transcribed much earlier during germ cell differentiation, then translationally repressed, and finally translated several days after the mRNA production, thanks to a complex interplay of RNA-binding proteins and non-coding RNA (for review, see Kleene (2013)). In this context, it is interesting to note the existence of the chromatoid body, a germ cell-specific RNA processing center suggested to be involved in the sequestration and translation repression of several mRNAs during spermiogenesis (Kotaja \& Sassone-Corsi 2007) and whose RNA and protein content was recently analyzed (Meikar et al. 2014). However, the direct contribution of this organelle to translational regulation remains to be clearly demonstrated (for review, see Kleene \& Cullinane (2011)).
More importantly, the use of cross-linking immunoprecipitation (CLIP) together with microarray analysis (CLIP-chip) or high-throughput sequencing (HITS-CLIP or CLIP-seq) has allowed some potential direct targets of RNA-binding proteins to be identified in male germ cells (Reynolds et al. 2005, Grellscheid et al. 2011, Vourekas et al. 2012, Zhang et al. 2015). The combination of such approaches with proteomic analyses of mutant mice would in turn help identify which mRNAs are actually translationally regulated by these specific factors during spermatogenesis.

Because of this prominent uncoupling between transcription and translation, the testis is often seen as an organ in which transcriptome and proteome are not necessarily linked. This low correlation between mRNA and protein concentrations within the testis was clearly evidenced in a tissue-profiling experiment that used multidimensional protein identification technology (MudPIT) for human tissue (Cagney et al. 2005). In this study, the abundance of 683 proteins and their corresponding transcripts were measured and compared in eight organs. Interestingly, the gene profiles of all organs clustered together, as did their protein profiles. This finding suggests that transcriptomes or proteomes from different organs are more similar than the transcriptome and proteome of the same organ. Importantly, the correlation between transcriptome and proteome data was weakest for the testis and highest for the liver (correlation coefficients of 0.138 and 0.432 respectively). To investigate the relation between proteins and mRNA levels during spermatogenesis in more detail, Gan et al. (2013a) used isolated type A spermatogonia, pachytene spermatocytes, round spermatids, and elongated spermatids for an iTRAQ-based proteomic analysis of male germ cell differentiation and compared their results with those of a previously published microarray dataset (Namekawa et al. 2006). While they found a consistent match for a subset of transcriptomic and proteomic profiles, they also observed that several regulation mechanisms including transcript degradation, translation repression, translation de-repression, and protein degradation affected most genes and may account for the low correlation between mRNAs and proteins, at both the mitosis/meiosis transition (Pearson correlation of 0.55) and the meiosis/post-meiosis transition (Pearson correlation of 0.41 ).

\section{Investigating the translatome of testicular cells}

Another exciting possibility for bridging the gap between gene expression and protein abundance lies in methods that allow investigation of the translatome, i.e. the measurement of transcripts that are actively processed by translational machinery (Fig. 1B). These analyses usually involve the purification of ribosomes or polysomes and the subsequent measurement of associated transcripts. 
Iguchi et al. (2006) first applied one such approach to address the question of translational regulation during the meiotic and post-meiotic phases of male germ cell development. The authors monitored the mRNAs associated with free RNPs and polysomes in the testes from mice at various postnatal stages and identified translationally up- and down-regulated transcripts, i.e. mRNAs significantly redistributed between free RNPs and the polysomal fraction during testis development. Not surprisingly, translation increased for most of these mRNAs, in elongating spermatids. This increase reflects a common mechanism compensating for the cessation of transcription from mid-spermiogenesis onwards. Nonetheless, they also identified a small cluster of meioticallyinduced mRNAs that were actively translated only in post-meiotic stages.

More recently, the development of genetically modified organisms that express an affinity-tagged ribosomal protein has provided a straightforward means of isolating ribosomes along with their bound mRNAs. Interestingly, the expression of these tagged proteins can be driven by a tissue/cell-specific promoter, such as the Cre-lox system in mice, which enables the capture of tagged ribosomes from an entire organ or tissue without the need to isolate the cells of interest (for review, see King \& Gerber (2014)). These methodologies, initially called translating ribosome affinity purification (TRAP) in the mouse (Doyle et al. 2008, Heiman et al. 2008), have been used several times to capture the translatome of various testicular cell types. For instance, Sanz et al. (2013) took advantage of Cyp17iCre and Amh-Cre mice to investigate the translatome of adult Leydig cells and Sertoli cells respectively. They also used this approach to investigate the regulation of Leydig cells by $\mathrm{LH}$ and that of Sertoli cells by FSH and testosterone in gonadotropindepleted mice. They notably found that the early response to $\mathrm{LH}$ (within $1 \mathrm{~h}$ ) was characterized by the induction of several transcription factors and genes involved in cell cycle while the secondary response to $\mathrm{LH}$ (after $4 \mathrm{~h}$ ) involved the up-regulation of genes involved in steroid metabolism and FGF signaling and the down-regulation of several transcription repressors. The regulatory role of testosterone was also successfully examined by De Gendt et al. (2014) who combined a TRAP approach that used Amh-Cre mice, a mouse model lacking a functional androgen receptor (AR) in Sertoli cells, and RNA-seq analysis. After determining the Sertoli cell translatomes of prepubertal and adult mice, which they found to be very similar, the authors compared these WT Sertoli cell translatomes to that of Sertoli cells lacking the AR and identified androgenregulated genes at the onset of meiosis, which included many plasma membrane and cytoskeleton factors involved in cell junction and adhesion. Finally, another study took advantage of this method to investigate the translatome of neonatal testicular germ cells at the onset of meiosis (Evans et al. 2014). Using a synchronized spermatogenesis model, the authors identified the changes in ribosome-bound mRNAs taking place in both differentiating spermatogonial cells (with Ngn3-Cre and Stra8-Cre mice) and maturing Sertoli cells (with Amh-Cre mice) after retinoic acid restoration.

Note that these ribosomal profiling analyses not only help to evaluate translation efficiency and estimate corresponding protein abundance more accurately than classical transcriptomic approaches, but, when coupled with RNA-seq, they can also provide information about ribosome occupancy, translation initiation, elongation, and termination at near-nucleotide resolution (for review, see Ingolia (2014)).

\section{From gene expression measurement to new testicular protein isoform prediction}

As mentioned previously, the measurement of steadystate gene expression does not necessarily estimate the actual proteome well. This is true from both the quantitative and qualitative points of view and especially for microarray experiments. Specifically, because microarrays measure gene expression through the sequencespecific hybridization of RNAs to DNA probes, they cannot gather information about transcript structure outside the sequence targeted by the probes. Furthermore, because most probes recognize several transcript isoforms, they report average gene expression and fail to identify the specific isoforms actually expressed in a given sample.

In this regard, the recent advance of RNA-seq technologies, together with the development of associated analysis pipelines, has revolutionized the field of transcriptomics. RNA-seq is an efficient and costeffective way to obtain large amounts of transcriptome data and identify both new genes and new isoforms, by the sequencing of novel exons and/or novel exonic junctions. RNA-seq thus makes it simultaneously possible to determine the structure of thousands of transcripts and to measure their abundance. Therefore, it provides a more accurate prediction of all corresponding protein isoforms (Fig. 1B). Several RNA-seq analyses have already been conducted to investigate spermatogenesis in rodents, with either isolated cells (Gan et al. 2013b, Soumillon et al. 2013, Chalmel et al. 2014b) or testes at various stages of the first wave of spermatogenesis (Laiho et al. 2013, Schmid et al. 2013, Margolin et al. 2014). All these studies have led to the reconstruction of a plethora of transcripts, including known isoforms but also thousands of new isoforms of known genes and hundreds of uncharacterized transcripts that correspond to either new coding or non-coding genes. The amount of information generated in such RNA-seq studies is so huge that a single study cannot undertake to report on all the exploration possibilities. For example, Chalmel et al. (2014b) restricted their analysis to novel unannotated loci and 
used four different bioinformatics tools to distinguish between transcripts with high and low coding potential. Margolin et al. (2014) initiated a broad analysis of splicing events by identifying transcripts that contained novel splice junctions in which the open reading frame (ORF) was maintained. Finally, Schmid et al. (2013) focused their study on the splicing dynamics of mRNAs in male germ cells, with a special emphasis on the newly identified splicing events that might affect protein isoform production during mouse meiosis, and identified significantly enriched motifs for PTB, TRA2B and STAR proteins in and around meiotically-regulated cassette exons. Therefore, although all these RNA-seq studies have highlighted many potential new protein-coding transcripts expressed in male germ cells, a thorough analysis aimed specifically at identifying the variants that actually code for specific proteoforms with distinct biological functions is still needed. Most importantly, the functional relevance and validity of these findings still require experimental validation at the protein level.

\section{Proteogenomic approaches applied to spermatogenesis}

Compared with microarrays, which are intrinsically limited to studying the expression of genes for which probes are spotted on their surface, MS-based proteomics has long been considered to be more powerful in the sense that theoretically it can detect and quantify any protein entity within a given sample. Protein identification, however, typically involves the comparison of experimental masses obtained by mass spectrometry to that of in silico-digested protein databases. Therefore proteomic studies are also limited to the sequence content of the database that is used for identification purposes. Several methods, called proteogenomics, have emerged to overcome this limitation and help identify novel peptides not present in reference protein sequence databases (for review, see Hernandez et al. (2014)). These methods rely on the construction of customized protein sequence databases that include, for example, products resulting from the six-frame translation of the reference genome or the three-frame translation of transcripts, or both, regardless of whether these correspond to known mRNAs, non-coding RNAs, or pseudogenes. Large consortia seeking to decipher the complete human proteome through the analysis of several human tissues, including the testis (Kim et al. 2014, Wilhelm et al. 2014), have recently used such approaches.

Among the most promising proteogenomic methods is RNA-seq-based proteogenomics, also called 'proteomics informed by transcriptomics' (PIT). The PIT strategy derives the customized protein sequence database queried for protein identification directly from RNA-seq data of the same or a similar sample (Evans et al. 2012). It therefore limits protein products in the custom database to those resulting from the three- or six-frame translation of the assembled transcripts that are indeed expressed in the organ, tissue, or cell type of interest. Compared with other proteogenomic approaches, PIT offers the advantage of a smaller database, which in turn reduces the number of false positives and increases sensitivity (Fig. 1A).

Recently, this strategy was applied to the identification of new proteins expressed during late stages of rat spermatogenesis (Chocu et al. 2014). In this study, protein extracts from isolated rat pachytene spermatocytes and round spermatids were first trypsin-digested and analyzed by nano LC-MS/MS. Next, MS/MS spectra were queried against a customized database derived from a previous RNA-seq analysis of rat testicular cells (Chalmel et al. 2014b), which had identified almost 12000 new transcript isoforms. It also reported the existence of more than 1400 completely new unannotated loci, most of them preferentially expressed in spermatocytes and/or spermatids. Because of this high gene discovery potential, Chocu et al. voluntarily restricted their PIT approach to meiotic and post-meiotic germ cells. This experiment led to the identification of 44 novel coding genes expressed during rat spermatogenesis, including 14 that were initially thought to correspond to non-coding RNAs. This approach has also been used to study the testicular proteome of the red abalone, Haliotis rufescens (Palmer et al. 2013) and allowed the identification of almost 1000 proteins. This number of proteins is especially remarkable when we consider that the number of UniProt entries still does not exceed 140 for this non-model species (Release 2014_11).

There is no doubt that the increasing performance of mass spectrometers and decreasing cost of RNA-seq will allow for rapid democratization of PIT studies and of proteogenomics in general. These approaches will be critical to the full characterization of both the transcriptome and the proteome of model organisms in various biological contexts, which in turn will help to annotate the corresponding genomes. PIT strategies are also a unique opportunity for non-model species, for which reference genome sequences are not available. Their transcriptomes and proteomes can be thoroughly examined without requiring the use of nucleic or protein sequence databases from phylogenetically distant species. Finally, regardless of the model of interest, the combination of RNA-seq and mass spectrometry into a PIT study offers a straightforward method of investigating the correlation of transcriptomes and proteomes, because protein profiles can be directly compared to transcript profiles on which protein identifications are also performed (for review, see Wang et al. (2014)).

\section{Conclusion}

The recent progress in next-generation sequencing technologies, together with the improved performance of mass spectrometers, has made possible a fruitful revisit of the testis genomic landscape. While we are 
now getting close to the complete identification of the molecular factors involved in spermatogenesis, an understanding of all the regulatory mechanisms that drive gene and protein expression during germ cell development and the identification of the key factors for male fertility both require additional work. This will notably imply the combination of all types of available data, i.e. from epigenomic, regulomic, transcriptomic, proteomic, and interactomic studies, in order to link the flow of information from DNA to functional proteins and non-coding RNAs. The success of this integrative work will also depend on the development of new types of web servers, such as the ReproGenomics Viewer (http:// rgv.genouest.org/; Darde et al. 2015), which allows the visualization, mining, and comparison of various types of omics data (e.g. ChIP-seq, RNA-seq, MS-based proteomics) in a multi- and cross-species manner. Finally, a current challenge in biology resides in the development of methods to investigate single cells at the genomic, transcriptomic, proteomic, and metabolomic level (for review, see Tsioris et al. (2014)). The use of these so-called single-cell approaches will mandate the more detailed study of the kinetics of germ cell differentiation and, most importantly, enable us to gain insight into the biology of discrete cell populations within the testis, such as the spermatogonial stem cell.

\section{Declaration of interest}

The authors declare that there is no conflict of interest that could be perceived as prejudicing the impartiality of the review.

\section{Funding}

This work was supported by the Institut national de la santé et de la recherche médicale (Inserm), the Université de Rennes 1, the Agence nationale de sécurité sanitaire de l'alimentation, de l'environnement et du travail (ANSES n ${ }^{\circ}$ EST-13-081 to $\mathrm{F}$ Chalmel), the Fondation pour la recherche médicale (FRM $\mathrm{n}^{\circ} \mathrm{DBI} 20131228558$ to $\mathrm{F}$ Chalmel), and the European Union (FEDER to $\mathrm{F}$ Chalmel).

\section{Acknowledgements}

We thank all members of the Institute for research in Health, Environment and Work for stimulating discussions.

\section{References}

Cagney G, Park S, Chung C, Tong B, O'Dushlaine C, Shields DC \& Emili A 2005 Human tissue profiling with multidimensional protein identification technology. Journal of Proteome Research 4 1757-1767. (doi:10.1021/pr0500354)

Calvel P, Rolland AD, Jégou B \& Pineau C 2010 Testicular postgenomics: targeting the regulation of spermatogenesis. Philosophical Transactions of the Royal Society of London. Series B, Biological sciences 365 1481-1500. (doi:10.1098/rstb.2009.0294)
Chalmel F, Rolland AD, Niederhauser-Wiederkehr C, Chung SS, Demougin P, Gattiker A, Moore J, Patard J-J, Wolgemuth DJ, Jégou B et al. 2007 The conserved transcriptome in human and rodent male gametogenesis. PNAS 104 8346-8351. (doi:10.1073/pnas.0701883104)

Chalmel F, Lardenois A, Evrard B, Mathieu R, Feig C, Demougin P, Gattiker A, Schulze W, Jégou B, Kirchhoff C et al. 2012 Global human tissue profiling and protein network analysis reveals distinct levels of transcriptional germline-specificity and identifies target genes for male infertility. Human Reproduction 27 3233-3248. (doi:10.1093/humrep/ des301)

Chalmel F, Com E, Lavigne R, Hernio N, Teixeira-Gomes A-P, Dacheux J-L \& Pineau C 2014a An integrative omics strategy to assess the germ cell secretome and to decipher Sertoli-germ cell crosstalk in the Mammalian testis. PLoS ONE 9 e104418. (doi:10.1371/journal.pone.0104418)

Chalmel F, Lardenois A, Evrard B, Rolland AD, Sallou O, Dumargne M-C, Coiffec I, Collin O, Primig M \& Jégou B 2014b High-resolution profiling of novel transcribed regions during rat spermatogenesis. Biology of Reproduction 91 5. (doi:10.1095/biolreprod.114.118166)

Chocu S, Calvel P, Rolland AD \& Pineau C 2012 Spermatogenesis in mammals: proteomic insights. Systems Biology in Reproductive Medicine 58 179-190. (doi:10.3109/19396368.2012.691943)

Chocu S, Evrard B, Lavigne R, Rolland AD, Aubry F, Jégou B, Chalmel F \& Pineau C 2014 Forty-four novel protein-coding loci discovered using a proteomics informed by transcriptomics (PIT) approach in rat male germ cells. Biology of Reproduction 91 123. (doi:10.1095/biolreprod.114. 122416)

Darde TA, Sallou O, Becker E, Evrard B, Monjeaud C, Le Bras Y, Jégou B, Collin O, Rolland AD \& Chalmel F 2015 The ReproGenomics Viewer: an integrative cross-species toolbox for the reproductive science community. Nucleic Acids Research 43 W109-W116. (doi:10.1093/ nar/gkv345)

De Gendt K, Verhoeven G, Amieux PS \& Wilkinson MF 2014 Research Resource: Genome-wide identification of AR-regulated genes translated in Sertoli cells in vivo using the RiboTag approach. Molecular Endocrinology 28 575-591. (doi:10.1210/me.2013-1391)

De la Grange P, Gratadou L, Delord M, Dutertre M \& Auboeuf D 2010 Splicing factor and exon profiling across human tissues. Nucleic Acids Research 38 2825-2838. (doi:10.1093/nar/gkq008)

Djureinovic D, Fagerberg L, Hallström B, Danielsson A, Lindskog C, Uhlén M \& Pontén F 2014 The human testis-specific proteome defined by transcriptomics and antibody-based profiling. Molecular Human Reproduction 20 476-488. (doi:10.1093/molehr/gau018)

Doyle JP, Dougherty JD, Heiman M, Schmidt EF, Stevens TR, Ma G, Bupp S, Shrestha P, Shah RD, Doughty ML et al. 2008 Application of a translational profiling approach for the comparative analysis of CNS cell types. Cell 135 749-762. (doi:10.1016/j.cell.2008.10.029)

Evans VC, Barker G, Heesom KJ, Fan J, Bessant C \& Matthews DA 2012 De novo derivation of proteomes from transcriptomes for transcript and protein identification. Nature Methods 9 1207-1211. (doi:10.1038/ nmeth.2227)

Evans E, Hogarth C, Mitchell D \& Griswold M 2014 Riding the spermatogenic wave: profiling gene expression within neonatal germ and Sertoli cells during a synchronized initial wave of spermatogenesis in mice. Biology of Reproduction 90 108. (doi:10.1095/biolreprod.114. 118034)

Fagerberg L, Hallström BM, Oksvold P, Kampf C, Djureinovic D, Odeberg J, Habuka M, Tahmasebpoor S, Danielsson A, Edlund K et al. 2014 Analysis of the human tissue-specific expression by genome-wide integration of transcriptomics and antibody-based proteomics. Molecular \& Cellular Proteomics 13 397-406. (doi:10.1074/mcp.M113. 035600)

Gan H, Cai T, Lin X, Wu Y, Wang X, Yang F \& Han C 2013a Integrative proteomic and transcriptomic analyses reveal multiple post-transcriptional regulatory mechanisms of mouse spermatogenesis. Molecular \& Cellular Proteomics 12 1144-1157. (doi:10.1074/mcp.M112.020123)

Gan H, Wen L, Liao S, Lin X, Ma T, Liu J, Song C-X, Wang M, He C, Han C et al. 2013b Dynamics of 5-hydroxymethylcytosine during mouse spermatogenesis. Nature Communications 4 1995. (doi:10.1038/ ncomms2995)

Grellscheid S, Dalgliesh C, Storbeck M, Best A, Liu Y, Jakubik M, Mende Y, Ehrmann I, Curk T, Rossbach K et al. 2011 Identification of evolutionarily 
conserved exons as regulated targets for the splicing activator tra2 $\beta$ in development. PLoS Genetics 7 e1002390. (doi:10.1371/journal.pgen. 1002390)

Heiman M, Schaefer A, Gong S, Peterson JD, Day M, Ramsey KE, SuárezFariñas M, Schwarz C, Stephan DA, Surmeier DJ et al. 2008 A translational profiling approach for the molecular characterization of CNS cell types. Cell 135 738-748. (doi:10.1016/j.cell.2008.10.028)

Hernandez C, Waridel P \& Quadroni M 2014 Database construction and peptide identification strategies for proteogenomic studies on sequenced genomes. Current Topics in Medicinal Chemistry 14 425-434. (doi:10.2174/1568026613666131204105652)

Hu Y-C \& Namekawa SH 2015 Functional significance of the sex chromosomes during spermatogenesis. Reproduction 149 R265-R277. (doi:10.1530/REP-14-0613)

Iguchi N, Tobias JW \& Hecht NB 2006 Expression profiling reveals meiotic male germ cell mRNAs that are translationally up- and down-regulated. PNAS 103 7712-7717. (doi:10.1073/pnas.0510999103)

Ingolia NT 2014 Ribosome profiling: new views of translation, from single codons to genome scale. Nature Reviews. Genetics 15 205-213. (doi:10.1038/nrg3645)

Kan Z, Garrett-Engele PW, Johnson JM \& Castle JC 2005 Evolutionarily conserved and diverged alternative splicing events show different expression and functional profiles. Nucleic Acids Research 33 5659-5666. (doi:10.1093/nar/gki834)

Khaitovich P, Hellmann I, Enard W, Nowick K, Leinweber M, Franz H, Weiss G, Lachmann M \& Pääbo S 2005 Parallel patterns of evolution in the genomes and transcriptomes of humans and chimpanzees. Science 309 1850-1854. (doi:10.1126/science.1108296)

Khil PP, Smirnova NA, Romanienko PJ \& Camerini-Otero RD 2004 The mouse $X$ chromosome is enriched for sex-biased genes not subject to selection by meiotic sex chromosome inactivation. Nature Genetics 36 642-646. (doi:10.1038/ng1368)

Kierszenbaum AL \& Tres LL 1975 Structural and transcriptional features of the mouse spermatid genome. Journal of Cell Biology 65 258-270. (doi:10.1083/jcb.65.2.258)

Kim M-S, Pinto SM, Getnet D, Nirujogi RS, Manda SS, Chaerkady R, Madugundu AK, Kelkar DS, Isserlin R, Jain S et al. 2014 A draft map of the human proteome. Nature 509 575-581. (doi:10.1038/ nature13302)

King HA \& Gerber AP 2014 Translatome profiling: methods for genomescale analysis of mRNA translation. Briefings in Functional Genomics [in press]. (doi:10.1093/bfgp/elu045)

Kleene KC 2013 Connecting cis-elements and trans-factors with mechanisms of developmental regulation of mRNA translation in meiotic and haploid mammalian spermatogenic cells. Reproduction 146 R1-R19. (doi:10.1530/REP-12-0362)

Kleene KC \& Cullinane DL 2011 Maybe repressed mRNAs are not stored in the chromatoid body in mammalian spermatids. Reproduction 142 383-388. (doi:10.1530/REP-11-0113)

Kotaja N \& Sassone-Corsi P 2007 The chromatoid body: a germ-cellspecific RNA-processing centre. Nature Reviews. Molecular Cell Biology 8 85-90. (doi:10.1038/nrm2081)

Kouadjo KE, Nishida Y, Cadrin-Girard JF, Yoshioka M \& St-Amand J 2007 Housekeeping and tissue-specific genes in mouse tissues. BMC Genomics 8 127. (doi:10.1186/1471-2164-8-127)

Laiho A, Kotaja N, Gyenesei A \& Sironen A 2013 Transcriptome profiling of the murine testis during the first wave of spermatogenesis. PLOS ONE 8 e61558. (doi:10.1371/journal.pone.0061558)

Margolin G, Khil PP, Kim J, Bellani MA \& Camerini-Otero RD 2014 Integrated transcriptome analysis of mouse spermatogenesis. BMC Genomics 15 39. (doi:10.1186/1471-2164-15-39)

McKee BD \& Handel MA 1993 Sex chromosomes, recombination, and chromatin conformation. Chromosoma 102 71-80. (doi:10.1007/ BF00356023)

Meikar O, Vagin VV, Chalmel F, Sõstar K, Lardenois A, Hammell M, Jin Y, Da Ros M, Wasik KA, Toppari J et al. 2014 An atlas of chromatoid body components. RNA 20 483-495. (doi:10.1261/rna.043729.113)

Mueller JL, Mahadevaiah SK, Park PJ, Warburton PE, Page DC \& Turner JM 2008 The mouse $X$ chromosome is enriched for multicopy testis genes showing postmeiotic expression. Nature Genetics 40 794-799. (doi:10.1038/ng.126)
Müller-McNicoll M \& Neugebauer KM 2013 How cells get the message: dynamic assembly and function of mRNA-protein complexes. Nature Reviews. Genetics 14 275-287. (doi:10.1038/nrg3434)

Namekawa SH, Park PJ, Zhang LF, Shima JE, McCarrey JR, Griswold MD \& Lee JT 2006 Postmeiotic sex chromatin in the male germline of mice. Current Biology 16 660-667. (doi:10.1016/j.cub.2006.01.066)

Palmer MR, Mcdowall MH, Stewart L, Ouaddi A, Maccoss MJ \& Swanson WJ 2013 Mass spectrometry and next-generation sequencing reveal an abundant and rapidly evolving abalone sperm protein. Molecular Reproduction and Development 80 460-465. (doi:10.1002/mrd.22182)

Papaioannou MD, Lagarrigue M, Vejnar CE, Rolland AD, Kühne F, Aubry F, Schaad O, Fort A, Descombes P, Neerman-Arbez M et al. 2011 Loss of Dicer in Sertoli cells has a major impact on the testicular proteome of mice. Molecular \& Cellular Proteomics 10 M900587MCP200. (doi:10.1074/mcp.M900587-MCP200)

Potrzebowski L, Vinckenbosch N, Marques AC, Chalmel F, Jégou B \& Kaessmann H 2008 Chromosomal gene movements reflect the recent origin and biology of therian sex chromosomes. PLoS Biology 6 e80. (doi:10.1371/journal.pbio.0060080)

Potrzebowski L, Vinckenbosch N \& Kaessmann H 2010 The emergence of new genes on the young therian X. Trends in Genetics 26 1-4. (doi:10.1016/j.tig.2009.11.001)

Rathke C, Baarends WM, Awe S \& Renkawitz-Pohl R 2014 Chromatin dynamics during spermiogenesis. Biochimica et Biophysica Acta 1839 155-168. (doi:10.1016/j.bbagrm.2013.08.004)

Reynolds N, Collier B, Maratou K, Bingham V, Speed RM, Taggart M, Semple CA, Gray NK \& Cooke HJ 2005 Dazl binds in vivo to specific transcripts and can regulate the pre-meiotic translation of Mvh in germ cells. Human Molecular Genetics 14 3899-3909. (doi:10.1093/ hmg/ddi414)

Rolland AD, Jégou B \& Pineau C 2008 Testicular development and spermatogenesis: harvesting the postgenomics bounty. Advances in Experimental Medicine and Biology 636 16-41. (doi:10.1007/978-0387-09597-4_2)

Rolland AD, Lavigne R, Dauly C, Calvel P, Kervarrec C, Freour T, Evrard B, Rioux-Leclercq N, Auger J \& Pineau C 2013 Identification of genital tract markers in the human seminal plasma using an integrative genomics approach. Human Reproduction 28 199-209. (doi:10.1093/humrep/ des360)

Sanz E, Evanoff R, Quintana A, Evans E, Miller JA, Ko C, Amieux PS, Griswold MD \& McKnight GS 2013 RiboTag analysis of actively translated mRNAs in Sertoli and Leydig cells in vivo. PLOS ONE 8 e66179. (doi:10.1371/journal.pone.0066179)

Schmid R, Grellscheid SN, Ehrmann I, Dalgliesh C, Danilenko M, Paronetto MP, Pedrotti S, Grellscheid D, Dixon RJ, Sette C et al. 2013 The splicing landscape is globally reprogrammed during male meiosis. Nucleic Acids Research 41 10170-10184. (doi:10.1093/nar/gkt811)

Solari AJ 1974 The behavior of the XY pair in mammals. International Review of Cytology 38 273-317. (doi:10.1016/S0074-7696(08)60928-6)

Soumillon M, Necsulea A, Weier M, Brawand D, Zhang X, Gu H, Barthès $P$, Kokkinaki M, Nef S, Gnirke A et al. 2013 Cellular source and mechanisms of high transcriptome complexity in the mammalian testis. Cell Reports 3 2179-2190. (doi:10.1016/j.celrep.2013.05.031)

Tsioris K, Torres AJ, Douce TB \& Love JC 2014 A new toolbox for assessing single cells. Annual Review of Chemical and Biomolecular Engineering 5 455-477. (doi:10.1146/annurev-chembioeng-060713-035958)

Turner JM 2007 Meiotic sex chromosome inactivation. Development 134 1823-1831. (doi:10.1242/dev.000018)

Uhlen $M$, Oksvold P, Fagerberg $L$, Lundberg $E$, Jonasson $K$, Forsberg $M$, Zwahlen M, Kampf C, Wester K, Hober S et al. 2010 Towards a knowledge-based Human Protein Atlas. Nature Biotechnology 28 1248-1250. (doi:10.1038/nbt1210-1248)

Uhlen $M$, Fagerberg L, Hallstrom BM, Lindskog C, Oksvold P, Mardinoglu A, Sivertsson A, Kampf C, Sjostedt E, Asplund A et al. 2015 Tissue-based map of the human proteome. Science 3471260419. (doi:10.1126/science.1260419)

Voolstra C, Tautz D, Farbrother P, Eichinger L \& Harr B 2007 Contrasting evolution of expression differences in the testis between species and subspecies of the house mouse. Genome Research 17 42-49. (doi:10.1101/gr.5683806)

Vourekas A, Zheng Q, Alexiou P, Maragkakis M, Kirino Y, Gregory BD \& Mourelatos Z 2012 Mili and Miwi target RNA repertoire reveals 
piRNA biogenesis and function of Miwi in spermiogenesis. Nature Structural \& Molecular Biology 19 773-781. (doi:10.1038/ nsmb.2347)

Wang G, Guo Y, Zhou T, Shi X, Yu J, Yang Y, Wu Y, Wang J, Liu M, Chen X et al. 2013 In-depth proteomic analysis of the human sperm reveals complex protein compositions. Journal of Proteomics 79 114-122. (doi:10.1016/j.jprot.2012.12.008)

Wang X, Liu Q \& Zhang B 2014 Leveraging the complementary nature of RNA-Seq and shotgun proteomics data. Proteomics 14 2676-2687. (doi:10.1002/pmic.201400184)

Wilhelm M, Schlegl J, Hahne H, Moghaddas Gholami A, Lieberenz M, Savitski MM, Ziegler E, Butzmann L, Gessulat S, Marx H et al. 2014 Mass-spectrometry-based draft of the human proteome. Nature $\mathbf{5 0 9}$ 582-587. (doi:10.1038/nature13319)

Wishart DS, Knox C, Guo AC, Cheng D, Shrivastava S, Tzur D, Gautam B \& Hassanali M 2008 DrugBank: a knowledgebase for drugs, drug actions and drug targets. Nucleic Acids Research 36 D901-D906. (doi:10.1093/ nar/gkm958)
Xu Q, Modrek B \& Lee C 2002 Genome-wide detection of tissue-specific alternative splicing in the human transcriptome. Nucleic Acids Research 30 3754-3766. (doi:10.1093/nar/gkf492)

Yeo G, Holste D, Kreiman G \& Burge CB 2004 Variation in alternative splicing across human tissues. Genome Biology 5 R74. (doi:10.1186/gb2004-5-10-r74)

Zhang P, Kang J-Y, Gou L-T, Wang J, Xue Y, Skogerboe G, Dai P, Huang DW, Chen R, Fu X-D et al. 2015 MIWI and piRNA-mediated cleavage of messenger RNAs in mouse testes. Cell Research 25 193-207. (doi:10. 1038/cr.2015.4)

Received 16 February 2015

First decision 16 March 2015

Revised manuscript received 17 July 2015

Accepted 13 August 2015 